\title{
We Hommage à J.-B. Pontalis
}

Marée basse marée haute ${ }^{[1]}$

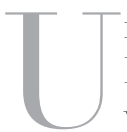

n livre posthume : telle est la forme la plus aboutie de la résurrection. Beaucoup en ont rêvé, toute leur vie étant orientée vers ce rêve. Certains y sont parvenus, Chateaubriand par ambition et orgueil, Camus, au hasard d'un accident de voiture et malgré lui.

Marée basse marée haute. Comment l'entendez-vous? "Mère est basse, mère est haute ". Mouvement de flux et de reflux rêvé par l'enfant inquiet de l'humeur maternelle, que Pontalis oriente à la hausse, vers le retour de l'eau sur le sable de la plage, l'eau bienfaisante et rafraîchissante, synonyme de vie après le reflux. Le retour de l'eau amène celui des baigneurs, des enfants et des mères qui surveillent les enfants, toujours inquiètes de la noyade, inquiètes que la mer ne les emporte à jamais. Insupportable séparation ! Le titre l'indique : la mer doit être haute, signe alors que la vie revient, que la vie ne peut pas mourir, que la mère non plus ne peut pas mourir. Les mouvements des marées sont comme la suite de nos jours, avec nos humeurs changeantes, tantôt hautes et tantôt basses. Les amours viennent, tantôt hautes, et les amours s'en vont, tantôt basses, comme nos vies.

Que reste-t-il de nous après notre mort? D'ailleurs faudrait-il plutôt écrire après la mort, tant ce phénomène ne peut se concevoir rapporté à nous : "Notre inconscient ne saurait se représenter notre propre mortalité » ne cessait de répéter Freud ${ }^{[2]}$. Quelle forme de nous conserveront nos proches? Comment accepter cette ultime séparation d'avec les êtres qui nous sont chers? Et surtout comment apprivoiser la plus insupportable : cette séparation d'avec nous-mêmes? Telles sont les questions que J.-B. Pontalis pose dans ce dernier livre qui l'a occupé avant de mourir et celles qu'il pose inlassablement depuis la publication d'un recueil d'articles intitulé Entre le rêse et la douleur (1977). Deux articles de ce beau recueil nous reviennent en mémoire en lisant ce dernier opus que Pontalis nous envoie de l'au-delà : “ Le mort et le vif entrelacés » et “Sur le travail de la mort ». Dans le premier, déjà partiellement

[1] Gallimard, 2013.

[2] Cité par Pontalis, Entre le rêve et la douleur. p. 247. 
autobiographique, Pontalis s'interrogeait sur les liens qui se tissent entre contretransfert et écriture. Patient travail de tissage dans le travail du contre-transfert, puis, en vacances d'analyse, travail de détricotage des liens entre l'analyste et ses patients. Mais alors, dans cette vacance de(s) patients et de l'analyste, l'écriture naît. Là aussi, flux et reflux : c'est dans cet écart entre Marée basse marée haute, dans cette respiration de l'analyse que naît l'écriture qui, chez Pontalis, n'est finalement pas séparable de l'analyse. Ce sont deux temps, inséparables l'un de l'autre, deux pulsations comme le flux et le reflux.

La question du deuil et de la séparation, il l'a rencontrée de nombreuses fois sur le divan : ce sont les voix de ses patients qu'il laissait résonner en lui, puis qu'il faisait résonner dans ses livres qui, à leur tour, résonnent en nous. Certaines de ses voix sont à jamais associées à Pontalis : celle de Perec, qu'il eut en analyse pendant la rédaction de W ou le Souvenir d'enfance, ce livre qu'il n'arrivait pas à finir. Perec trop tôt disparu, et qui n'a cessé de hanter les livres du psychanalyste J.-B. Pontalis.

Ecrire aide-t-il à mourir ? Ecrire aide-t-il à lutter contre la mort à l'œuvre ? Voilà certainement une question freudienne, ou plutôt LA question que Freud n'a cessé de se poser à lui-même depuis la Traumdeutung et celle qui l'a accompagné dans ce patient travail de la mort en lui. C'est peut-être aussi grâce à l'écriture qu'il a supporté son cancer pendant près de vingt ans. J.-B. Pontalis revient sur cette question dans le second article auquel nous renvoie la lecture de Marée basse marée haute, "Sur le travail de la mort ». Il y cite Freud : "Dans l'inconscient, il n'y a rien qui puisse donner un contenu à notre concept de destruction. Je me tiens fermement à l'idée que l'angoisse de mort doit être conçue comme un analogon de l'angoisse de castration " ${ }^{[3}$. Sur le modèle du traumarbeit (travail du rêve analysé par Freud dans la Traumdeutung), puis sur celui du “ travail du deuil »(Lagache, 1938), Pontalis propose le travail de la mort en nous : "A la question : par quoi nous, individus, sommes-nous vécus ? [...], la première réponse implicite pourrait se formuler ainsi : nous sommes vécus par la mort " ${ }^{[4]}$. Ainsi la mort n'est-elle plus l'ultime étape, redoutée ou attendue, elle est la trame même de nos vies.

Ecrire un ultime ouvrage, l'offrir à ses amis, à ses amours, à ses lecteurs, quatre mois jour pour jour après sa mort : quelle élégance! Comme s'il voulait se délivrer de cette ultime impolitesse : nous avoir fait faux bond.

Les psychanalystes sont finalement des philosophes comme les autres - enfin, certains psychanalystes. Ils écoutent leurs patients, qui n'en finissent pas d'interroger la mort qui leur est insupportable, et, comme Montaigne, parfois ils pourraient leur dire « que philosopher, c’est apprendre à mourir ». Pontalis ouvre Marée basse marée haute sur un chapitre intitulé : “ Le commandant ». C'est un vieil homme, autrefois

[3] S. Freud (1926), Inhibition, symptôme et angoisse, cité par J.-B. Pontalis Entre le rêve et la douleur, Tel, Gallimard, 1977, p. 247.

[4] J.-B. Pontalis, op.cit., p. 243. C'est Pontalis qui souligne. 
commandant de navire, qui, à la suite d'une faute de navigation, s'est vu retirer son autorisation de naviguer. Vieilli, abandonné par sa femme et sans enfant, mais toujours digne et impeccablement habillé, “ il regarde la mer et les enfants excités qui courent et se renversent sur le sable. Son regard scrute l'horizon, se perd dans le lointain, puis revient vers le plus proche, les cris des enfants " ${ }^{[5]}$.

J.-B. Pontalis est mort le 14 janvier 2013, veille de son anniversaire, on l'a souvent fait remarquer. La mer s'est alors arrêtée et J.-B. n'a pas voulu repartir surveiller la plage, comme le capitaine du début du livre. Mais J.-B. Pontalis n'est pas - tout à fait - mort. Sa voix ne cesse et ne cessera jamais de résonner en nous : ses livres nous accompagnent, jouant en sourdine leur mélodie dans nos vies. Freud avait raison : pour l’inconscient, la mort n'existe pas. “ La vie s'éloigne mais elle revient „ ${ }^{[6]}$.

Mariane Perruche

[5] J.-B. Pontalis, Marée basse marée haute, Paris, Gallimard, 2013, p. 14

[6] Idem, p. 137. 